\section{JURNAL ABDIMAS

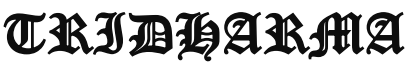

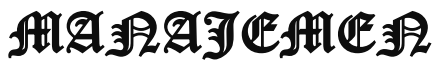

\title{
PERANAN KOMUNIKASI PADA SEBUAH ORGANISASI YANG BERTUJUAN MENINGKATKAN MOTIVASI
}

\author{
Sri Sukapti, Styo Budi Utomo, M. Zaenal Muttaqin Abdi, \\ Sonny, Widya Candra Dewi \\ Dosen Fakultas Ekonomi Universitas Pamulang \\ Email: dosen02318@unpam.ac.id, dosen01759@unpam.ac.id, \\ dosen00950@unpam.ac.id, dosen00983@unpam.ac.id, \\ dosen0281@unpam.aci.id
}

\begin{abstract}
ABSTRAK
Pengabdian Kepada Masyarakat (PKM) ini bertujuan untuk memberikan pengetahuan kepada para siswa khususnya calon dan pengurus Organisasi Siswa Intra Sekolah (OSIS) di SMK Al Amanah, Kecamatan Setu, Kota Tangerang Selatan tentang bagaimana mengelola dan mengembangkan organisasi. Selain itu memberikan pengetahuan akan pentingnya pola komunikasi di dalam organisasi. Kemudian para siswa juga diberikan wawasan tentang bagaimana meningkatkan motivasi di dalam berorganisasi.

Sasaran kegiatan PKM adalah para siswa-siswi SMK Al Amanah, khususnya para calon dan pengurus OSIS serta guru yang menjadi pembina OSIS. Permasalahan diselesaikan melalui tiga (3) tahapan yaitu: persiapan, pelaksanaan dan evaluasi. Tahap persiapan diawali dengan melakukan survei lokasi untuk memeroleh informasi terkait kebutuhan para siswa dan pengurus OSIS sekaligus membangun komunikasi dengan civitas sekolah seperti kepala sekolah dan guru yang merupakan pembina OSIS. Tahap pelaksanaan difokuskan untuk menyiapkan semua kebutuhan kegiatan, seperti membuat rancangan anggaran biaya, proposal, penyusunan materi dan menyiapkan alat kelengkapan. Tahap evaluasi dilakukan dengan mengumpulkan dan menyimpulkan data dari masing-masing tahapan kegiatan.

Hasil kegiatan berjalan sesuai dengan yang diharapkan. Hal ini terlihat dari antusias para peserta. Para peserta memeroleh input dari materi-materi yang disampaikan yang meliputi materi keorganisasian, komunikasi dan motivasi. Kegiatan juga mendapat dukungan penuh dari para civitas sekolah di antaranya: kepala sekolah dan para guru yang menjadi pembina OSIS. Kegiatan ini dinilai menambah khazanah keilmuan bagi para siswa lantaran tidak diperoleh di proses belajar kelas.
\end{abstract}

Kata kunci: organisasi, komunikasi, motivasi, OSIS, Kota Tangerang Selata

\begin{abstract}
ABSTRAC
Community Service (PKM) aims to provide knowledge to students, especially candidates and administrators of the Intra-School Student Organization (OSIS) at Al Amanah Vocational School, Setu District, South Tangerang City about how to manage and develop organizations. Besides providing knowledge of the importance of communication patterns in the organization. Then students are also given insights on how to increase motivation in organizing.

The targets of PKM activities are the students of Al Amanah Vocational School, especially the candidates and administrators of the Student Council and teachers who are the coaches of the Student Council. The problem is solved through three (3) stages, namely: preparation, implementation and evaluation. The preparation phase begins with conducting a site survey to obtain information related to the needs of students and student
\end{abstract}




\section{JURNAL ABDIMAS

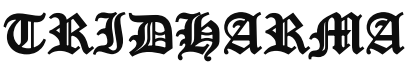

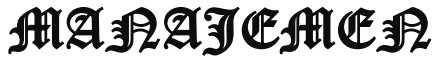

P-ISSN 2715-7105, E-ISSN 2716-070X

Jurnal ABDIMAS Vol. 1, No.2,Mei 2020, Hal (16-24)

@ Prodi Manajemen Fakultas Ekonomi Universitas Pamulang

Email: abdimasjurnal.unpam @ gmail.com Telp: (021) 741-2566

council officials as well as building communication with the school community such as school principals and teachers who are council coaches. The implementation phase is focused on preparing all the activity needs, such as making a draft budget, proposals, preparing materials and preparing equipment. The evaluation phase is carried out by collecting and concluding data from each stage of the activity.

The results of activities run as expected. This can be seen from the enthusiasm of the participants. The participants obtained input from the material presented which included organizational, communication and motivation material. The activity also received full support from the school community including: the principal and the teachers who became the student council coach. This activity is considered to increase scientific treasures for students because it is not obtained in the classroom learning process.

Keywords: organization, communication, motivation, OSIS, Kota Tangerang Selatan

\section{PENDAHULUAN}

Pengertian organisasi secara umum adalah perkumpulan atau wadah bagi sekelompok orang untuk bekerja sama, terkendali dan terpimpin untuk tujuan tertentu .Organisasi biasanya memanfaatkan sumber daya yang ada dalam rangka mencapai tujuan organisasi.Untuk mencapai tujuan organisasi tersebut, biasanya orang-orang di dalam organisasi sepakat melakukannya secara sistematis, rasional, terkendali dimana ditunjuk seorang pemimpin yang akan memimpin operasional organisasi dengan terencana.

Stoner menjelaskan bahwa organisasi adalah suatu pola hubungan-hubungan yang melalui mana orang-orang di bawah pengarahan manajer mengejar tujuan bersama. Menurut James D. Mooney, organisasi adalah bentuk setiap perserikatan manusia untuk mencapai tujuan bersama. Menurut Chester I. Bernard organisasi merupakan suatu system aktivitas kerjasama yang dilakukan oleh dua orang atau lebih. Struktur organisasi adalah susunan komponenkomponen (unit-unit kerja) dalam organisasi.

Struktur organisasi merupakan deskripsi bagaimana organisasi membagi pekerjaan dan melaksanakan tugas atau pekerjaannya dalam rangka mencapai tujuan organisasi.Struktur organisasi juga mengatur siapa yang melaksanakan tugas dan pekerjaan itu.Selain membagi dan mengatur tugas dan pekerjaan yang diemban oleh organisasi, struktur organisasi juga menggambarkan hubungan organisasi secara internal maupun eksternal.

Paul Preston dan Thomas Zimmerer mengatakan bahwa organisasi adalah sekumpulan orang-orang yang disusun dalam kelompok-kelompok, yang bekerjasama untuk mencapai tujuan bersama. (Organization is a collection people, arranged into groups, working together to achieve some common objectives).

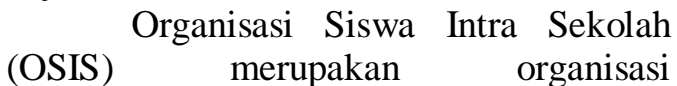
sekolah.Organisasi dalam hal ini OSIS merupakan satuan atau kelompok kerjasama para siswa yang dibentuk dalam usaha mencapai tujuan bersama, yaitu mendukung terwujudnya pembinaan kesiswaan.Dalam hal ini OSIS dipandang sebagai suatu sistem, dimana sekumpulan para siswa mengadakan koordinasi dalam upaya menciptakan suatu organisasi yang mampu mencapai tujuan.OSIS sebagai suatu system ditandai beberapa cirri pokok, berorientasi pada tujuan, memiliki susunan kehidupan kelompok, memiliki sejumlah peranan, terkoordinasi, dan berkelanjutan dalam waktu tertentu.Sebagai salah satu jalur dari pembinaan kesiswaan, fungsi OSIS adalah sebagai wadah, motivator, dan preventif.

Dampak yang ditimbulkan dengan adanya OSIS adalah mengikuti 


\section{JURNAL ABDIMAS

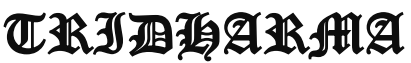

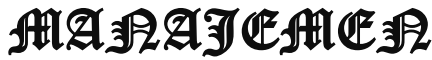

P-ISSN 2715-7105, E-ISSN 2716-070X

Jurnal ABDIMAS Vol. 1, No.2,Mei 2020, Hal (16-24)

@ Prodi Manajemen Fakultas Ekonomi Universitas Pamulang

Email: abdimasjurnal.unpam @ gmail.com Telp: (021) 741-2566 kepengurusan OSIS, menambah rasa percayadiri, meningkatkan rasa kebersamaan, memiliki banyak pengalaman, cepat menemukan problem solving dalam menghadapi permasalahan, memiliki jiwa sosial yang tinggi (dampak positif).Sedangkan dampak negatifnya adalah sulit membagi waktu antara belajar dan organisasi, jarang mengikuti pelajaran di kelas, prestasi belajar menurun, memiliki teman hanya dalam kelompok tertentu.Kemudian di dalam organisasi tidak juga terlepas dari konflik, baik internal maupun eksternal.

Tantangan eksternal terbaru yang sekarang menjadi persoalan bersama adalah masuknya ajaran-ideologi yang berorientasi menggantikan Pancasila dan Negara Kesatuan Republik Indonesia (NKRI).Sejumlah dampak yang terjadi atas berkembangnya ajaran-ideologi tersebut memicu pola komunikasi yang buruk parasiswa, baik itu antar-sesamasiswa, civitas sekolah, orang tua dan masyarakat sekitar.Ajaran-idelogi tersebut dikhawatirkan meruntuhkan nilai-nilai moral, etika, norma, budaya dalam kehidupan bermasyarakat khususnya bagi siswa dan tak lepas di internal organisasinya (OSIS).

Untuk itu juga amat menjadi penting bagi para siswa untuk diberikan pengetahuan mengenai proses menyelesaikan konflik internal maupun eksternal yang menjadi tantangan OSIS. Konflik internal yang biasa terjadi di dalam organisasi semisal kesalah pahaman antar-anggota, factor struktur tugas maupun struktur organisasi, seperti ketidaksamaan keinginan antara bendahara dan ketua, faktor yang bersifat personal, seperti individu harus membuat keputusan yang menyangkut dirinya dan organisasi, factor lingkungan seperti tidak adanya dukungan dari lingkungan atau pihak- pihak tertentu (civitas sekolah).

Struktur Organisasi sangat penting untuk dapat dipahami oleh semua komponen dalam rangka menciptakan system kerja yang efektif dan efesien.Struktur organisasi merupakan deskripsi bagaimana organisasi membagi pekerjaan dan melaksanakan tugas atau pekerjaannya dalam rangka mencapai tujuan organisasi.Struktur organisasi juga mengatur siapa yang melaksanakan tugas dan pekerjaan itu.Selain membagi dan mengatur tugas dan pekerjaan yang diemban oleh organisasi, struktur organisasi juga menggambarkan hubungan organisasi secara internal maupuneksternal.

Kondisi atau situasi yang tergambar di atas, bisa jadi juga dialami para siswa khususnya para pengurus OSIS di SMK Al Amanah, di Kecamatan Setu, Kota Tangerang Selatan.Berdasarkan analisis situasi ini lah akhirnya kegiatan Pengabdian Kepada Masyarakat (PKM) focus pada bagaimana memberikan pengetahuan, pemahaman kepada para siswa khususnya calon maupun pengurus OSIS di SMK Al Amanah tentang organisasi, komunikasi dan motivasi dengan mengangkat tema: "PERANAN KOMUNIKASI PADA SEBUAH ORGANISASI YANG BERTUJUAN MENINGKATKAN MOTIVASI."

\section{RUMUSAN MASALAH}

Dengan mempertimbangkan latar belakang yang telah diutarakan diatas kami berinisiatif untuk membentuk kegiatan pengabdian masyarakat bagi siswa-siswi SMK Al-Amanah jurusan Administrasi Perkantoran.

Membekali siswa - siswi dengan memberikan pemahaman tentang organisasi, komnuikasi, dan motivasi kepada siswa-siswi SMK Al-Amanah jurusan Administrasi Perkantoran agar mudah dipahami dan mampu mengelola, organisasi sekolah (OSISI) secara mandiri dan professional.

\section{TUJUAN PELAKSANAAN}

1. Membantu memberikan arahan pada siswa - siswi SMK Al-Amanah khususnya kelas X jurusan Administrasi Perkantoran.

2. Membuka paradigma siswa-siswi terkait dengan penting peran organisasi, 


\section{JURNAL ABDIMAS

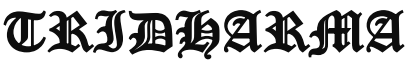

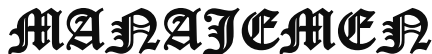

P-ISSN 2715-7105, E-ISSN 2716-070X

Jurnal ABDIMAS Vol. 1, No.2,Mei 2020, Hal (16-24)

@ Prodi Manajemen Fakultas Ekonomi Universitas Pamulang

Email: abdimasjurnal.unpam @ gmail.com Telp: (021) 741-2566 komunikasi, dan motivasi dalam kegiatan OSIS

3. Memberikan semangat dan motivasi bagi siswa-siswi SMK Al-Amanah dalam meniti karir di kemudian hari.

\section{TINJAUAN PUSTAKA}

\section{Pengertian Komunikasi}

Secara estimologis, komunikasi berasal dari bahasa Latin "Cum" sebuah kata depan yang diartikan "dengan" atau "bersama," dan "units" sebuah kata bilangan yang berarti "satu."Dua kata tersebut membentuk "communion" diartikan kebersamaan, persatuan, persekutuan, gabungan, pergaulan atau hubungan.

1. Karena ber-communio diperlukan adanya usaha dan kerja, kata itu dibuat menjadi kata kerja communicate yang berarti membagi sesuatu dengan seseorang, tukar-menukar, membicarakan sesuatu dengan orang, memberitahukan sesuatu kepada seseorang, bercakap-cakap, bertukarpikiran, berhubungan, berteman.

2. Jadi komunikasi berarti pemberitahuan, pembicaraan, percakapan, pertukaran pikiran atau hubungan (Hardjana, 2003).

\section{Longman Dictionary of Contemporary}

Englishmemberikan definisi communicate sebagai membuat pendapat, mengatakan perasaan, menyampaikan informasi, dan sebagainya, agar diketahui atau dipahami oleh orang lain .

Arti lain yang dikemukakan dalam kamus adalah berbagi (to share) atau bertukar (to cxchange) pendapat, perasaan, informasi, dan sebagainya. Adapun communication dapat diartikan sebagai tindakanatau proses berkomunikasi.

\section{PengertianOrganisasi}

Kata dalam bahasa Inggris "Organization" oleh sejumlah ahli dikatakan sebagai asal kata "organisasi." Namun jika dirunut lebih jauh, sebenarnya akar katanya berasal dari bahasa Latin "organizare", yang kemudian di dalam bahasa Inggris menjadi "organize." "Organize" diartikan sebagai upaya bangun - membangun. Bisa juga dimaknai membentuk. Membentuk dalam artian suatu kesatuankebulatan - lingkaran-lingkaran (o) yang menyatu. Jadi, bagian-bagian, satuan-satuan yang menyatu dengan lainnya. Jadi organisasi semestinya menjadi kesatuanyang kuat. Saling menguatkan satu dengan lainnya.

\section{PengertianMotivasi}

Motivasi didefinisikan sebagai serangkaian proses yang menggerakan, mengarahkan, dan mempertahankan perilaku individu untuk mencapai beberapa tujuan (Greenberg \& Baron, 2003).

Motivasi adalah proses yang ikut menentukan intensitas, arah dan ketentuan individu dalam usaha mencapai sasaran (Robbins, 2006).

Motivasi memiliki dimensi yang berlangsung lama. Ini adalah ukurang tentang berapa lama seseorang dapat mempertahankan usahanya. Individuindividu yang termotivasi tetap bertahan dengan pekerjaannya dalam waktu lama untuk mencapai sasaran mereka.

\section{METODE PELAKSANAAN}

Metode kegiatan yang digunakan dalam kegiatan PKM ini menggunakan beberapa cara, antara lain :

1. Video Based Learning, adalah penyampaian materi menggunakan video.

2. Metode persentasi/ceramah, pemateri menyajikan presentasi tentang komunikasi, organisasi dan motivasi. 


\section{JURNAL ABDIMAS

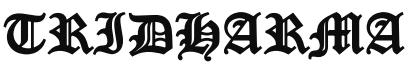

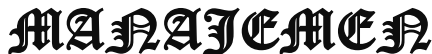

P-ISSN 2715-7105, E-ISSN 2716-070X

Jurnal ABDIMAS Vol. 1, No.2,Mei 2020, Hal (16-24)

@ Prodi Manajemen Fakultas Ekonomi Universitas Pamulang

Email: abdimasjurnal.unpam @ gmail.com Telp: (021) 741-2566
3. Metode tanya jawab, adalah metode yang digunakan untuk merespon sejauh mana tingkat pemahaman peserta tentang materi yang telah disampaikan oleh narasumber.

4. Metode diskusi, adalah metode yang digunakan untuk memecahkan setiap permasalahan yang dikemukakan oleh peserta

\section{HASIL DAN PEMBAHASAN}

Sebelum menyampaikan hasil dan pembahasan dalam kegiatan Pengabdian Kepada Masyarakat (PKM) di SMK Al Amanah, Setu, Kota Tangerang Selatan, sekadar mengingatkan kembalik bahwa pelaksanaan PKM ini dilakukan dengan tiga (3) tahap:

1) Tahap persiapan. Pada tahapan ini dilakukan survei lokasi, melihat langsung kondisi situasi objek, agar memeroleh informasi terkait tingkat kebutuhan para siswa dan pengurus OSIS. Dalam tahap ini juga, para dosen berkomunikasi dengan civitas sekolah, yakni Kepala Sekolah, guru-guru, dan pengurus OSIS.

2) Tahap pelaksanaan. Pada tahapan ini difokuskan pada menyiapkan semua kebutuhan kegiatan. Semisal membuat rancangan anggaran biaya (RAB), proposal PKM, penyusunan materi pelatihan tentang keorganisasian, komunikasi di dalam organisasi, dan motivasi oleh tim/kelompok.

\section{3) Selanjutnya}

mensinkronisasi waktu pelaksanaan kegiatan oleh pihak sekolah, yang direncanakan pada pertengahan Oktober 2019 (tanggal masih tentatif). Komunikasi dengan pihak sekolah juga berkaitan dengan izin yang diberikan kepada tim/kelompok (Dosen Universitas Pamulang) untuk melaksanakan PKM di SMK Al Amanah, Tangerang Selatan. Selanjutnya tim menyiapkan alat kelengkapan pelatihan (ATK, Spanduk, konsumsi, piagam, plakat, makalah, dll).

4) Tahap evalusi. Pada tahap ini dilakukan evaluasi atas hasil yang dicapai oleh peserta pelatihan. Evaluasi dilakukan dengan mengumpulkan data yang diperoleh dari kegiatan pelatihan. Data diperoleh dengan menarik kesimpulan pemahaman para pengurus OSIS.

5) Tahap penyusunan laporan. Pada tahap ini pelaksana PKM melaporkan kegiatannya kepada pihak Universitas Pamulang (Unpam) sekaligus sebagai bentuk pertanggungjawaban sekaligus mengetahui keluaran yang diharapkan.

Dengan tahapan tersebut, akhirnya kegiatan PKM akhirnya bisa terlaksana, tepatnya pada tanggal 21-23 Oktober 2019 yang secara umum hasilnya bisa dikategorikan baik. Pihak sekolah sendiri menyambut positif kegiatan PKM. Hal itu bisa dibuktikan dengan kesiapan pihak sekolah ikut andil menyediakan segala segala sesuatunya yang dibutuhkan.

Mulai dari penyediaan tempat, peralatan pelatihan, pola komunikasi dengan tim PKM dosen Unpam dan dorongan agar para siswa mengikuti kegiatan. Antusias para siswa juga tergambar dengan membludaknya jumlah kepersertaan. Bukan hanya para siswa, khususnya para pengurus OSIS, para guru yang memosisikan diri sebagai pendamping juga ikut aktif saat forum berlangsung.

Dukungan juga tampak dari para pejabat teras di SMK Al Amanah. Seperti yang disampaikan oleh Kepala SMK Al Amanah Bapak Ahmad Muhroj yang menegaskan bahwa kegiatan PKM tersebut juga bagian dari implementasi program yang digalakkan Dinas Pendidikan Kota Tangerang Selatan. Dimana sekolah diminta untuk menambah konten-konten pengetahuan yang mendukung kegiatan- 


\section{JURNAL ABDIMAS

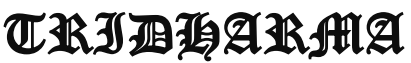

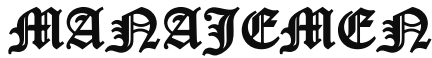

P-ISSN 2715-7105, E-ISSN 2716-070X

Jurnal ABDIMAS Vol. 1, No.2,Mei 2020, Hal (16-24)

@ Prodi Manajemen Fakultas Ekonomi Universitas Pamulang

Email: abdimasjurnal.unpam @ gmail.com Telp: (021) 741-2566 kegiatan di sekolah, terlebih para pengurus OSIS. Ia juga mengatakan bahwa penguatan mengenai organisasi, komunikasi dan motivasi memang sangat diperlukan khususnya bagi calon pengurus dan pengurus OSIS. Materi PKM yang disampaikan para narasumber, yaitu para dosen Unpam, kata dia, setara dengan materi Latihan Dasar Kepemimpinan (LDK) yang biasa diberikan kepada calon pengurus OSIS.

Pada saat forum berlangsung, terlihat dengan jelas sekali para siswa sangat tertarik dengan materi-materi yang disampaikan para narasumber. Hal ini terlihat dari begitu banyaknya para siswa mengajukan pertanyaan. Yang tadinya satu sesi pertanyaan hanya diperuntukkan untuk tiga penanya, justru jumlah siswa yang bertanya melebihi dari apa yang diprediksikan.

Kegiatan PKM yang dilaksanakan, khususnya untuk kalangan pelajar menurut Ketua Tim PKM Sri Sukapti S.Pd, M.M. merupakan salah satu kewajiban dosen untuk berkontribusi secara nyata bagi pembangunan intelektual generasi muda. Menurutnya pembekalan kepada pelajar tersebut masih sangat relevan dengan perkembangan zaman hari ini, khususnya mendidik kepada pelajar bagaimana menjadi organisatoris handal. Demikian dikatakan Sri Sukapti saat memberikan sambutan dihadapan para civitas sekolah dan peserta sekaligus mendampingi Kepala SMK Al Amanah untuk membuka kegiatan PKM. Dengan PKM ini kami berharap para siswa menjadi organisatoris sekaligus motivator handal. Dengan bergorganisasi, para siswa akan mendapatkan banyak ilmu, pengetahuan, wawasan di luar pelajaran sekolah," demikian dikatakan Sri Sukapti. PKM yang mengangkat tema "Peran Komunikasi pada Sebuah Organisasi yang Bertujuan Meningkatkan Motivasi" ini diisi dengan diskusi mengenai seluk-beluk organisasi, bagaimana mengurusnya, bagaimana membangun komunikasi yang baik sesama anggota organisasi, dan bagaimana motivasi dalam berkelompok. Hal ini juga berkaitan dengan dasar-dasar kepemimpinan.

Dalam pelaksanaan forum yang digelar di lantai 2 aula SMK Al Amanah yang dimulai pada pukul: $13.00 \mathrm{~s} / \mathrm{d} 17.00$ Wib, para narasumber menyampaikan setidaknya tiga (3) materi, yang menyangkut mengenai keorganisasian, komunikasi dan motivasi. Di masingmasing penyampaian materi ada sesi tanya jawab. Berikut materinya:

1. Materi I tentang keorganisasian yang disampaikan oleh Bapak Sonny, S.E, M.Si, yang meliputi: pengertian organisasi, bentuk-bentuk organisasi, tujuan dan manfaat organisasi dan ciri-ciri organisasi.

2. Materi II tentang komunikasi yang dipaparkan oleh Ibu Widya Candra S.E, MM yang meliputi: pengertian komunikasi, bentuk-bentuk komunikasi, tujuan komunikasi, fungsi dan peran komunikasi.

3. Materi III tentang motivasi yang dikemukakan oleh Bapak Styo Budi Utomo, S.PdI, M.M meliputi: pengertian motivasi, fungsi dan pentingnya motivasi dan faktor-faktor motivasi.

4. Materi IV diisi dengan mereview materi sekaligus kuis/games :

dipimpin langsung oleh Bapak

Zaenal Muttaqin Abdi, S.E, M.M.

Pada sesi ini bagi peserta yang mampu menjawab pertanyaanpertanyaan yang diajukan oleh narasumber diberikan doorprize.

Usai pemaparan materi, kegiatan dilanjutkan dengan penyampaian harapanharapan oleh Kepala SMK Al Ame 22 Bapah Ahmad Muhroj, Ketua Tim P Ibu Sri Sukapti S.Pd, M.M, dan perwakilan siswa. Kepala SMK Al Amanah juga didapuk untuk memimpin doa penutup. Usai doa penutup, sesi selanjutnya adalah penyerahan cinderamata dari pihak Unpam yang diwakili Ketua Tim PKM Ibu Sri Sukapti S.Pd, M.M. kepada Kepala SMK Al 


\section{JURNAL ABDIMAS

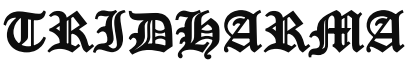

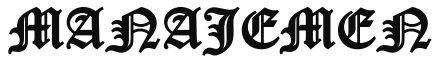

P-ISSN 2715-7105, E-ISSN 2716-070X

Jurnal ABDIMAS Vol. 1, No.2,Mei 2020, Hal (16-24)

@ Prodi Manajemen Fakultas Ekonomi Universitas Pamulang

Email: abdimasjurnal.unpam @ gmail.com Telp: (021) 741-2566
Amanah Bapak Ahmad Muhroj yang dilanjutkan dengan foto bersama.

Dalam kesempatan ini, tim PKM juga berkesempatan mengirim pers rilis yang dikirimkan ke email redaksi sejumlah media online lokal sebagai target dari luaran program ini. Berikut link pemberitaan di media online-nya:

a. Memoonline.co.id, dengan judul pemberitaan "PKM Tangsel Dorong Siswa-Siswi SMK Al Amanah menjadi Organisatoris dan Motivator." Link: (http://www.memoonline.co.id/read/5 325/20191113/223146/pkm-tangseldorong-siswa-siswi-smk-al-amanahmenjadi-organisatoris-danmotivator/).

b. Tangseloke.com, dengan judul pemberitaan "Dosen Unpam Latih Pelajar SMK Jadi Organisatoris Handal." Link: (https://tangseloke.com/2019/11/14/d osen-unpam-latih-pelajar-smk-jadiorganisatoris-handal/).

c. Wartaindonesia.co.id, dengan judul pemberitaan "Dosen Unpam Tantang Pelajar Jadi Aktivis Organisasi." Link: (https://wartaindonesia.co.id/dosenunpam-tantang-pelajar-jadi-aktivisorganisasi/).

d. Media merdeka.com, dengan judul pemberitaan "Dorong Siswa Jadi Organisatoris dan Motivator." Link: (http://media-

merdeka.com/2019/dorong-siswa-

jadi-organisatoris-dan-

motivator.html).

e. Kabarindong.com, dengan judul pemberitaan "Dosen Unpam Ajarkan Pelajar Jadi Organisatoris." Link: (http://kabarindong.com/humaniora/d osen-unpam-ajarkan-pelajar-jadiorganisatoris/).

f. Kabartangsel.com, dengan judul pemberitaan "Dosen Unpam Dorong Siswa Jadi Organisatoris dan Motivator." Link: (https://kabartangsel.com/dosen- unpam-dorong-siswa-jadiorganisatoris-dan-motivator/).

g. Kabar9.net dengan judul pemberitaan "Dosen Unpam Tantang Pelajar Jadi Aktivis Organisasi." Link: (http://kabar9.net/dosen-unpamtantang-pelajar-jadi-aktivisorganisasi/).

h. Palapanews.com dengan judul pemberitaan "Siswa Didorong Jadi Organisatoris dan Motivator." Link: (https://palapanews.com/2019/11/13/s iswa-didorong-jadi-organisatoris-danmotivator/).

\section{KESIMPULAN DAN SARAN}

\section{Kesimpulan}

Kegiatan PKM yang dilaksanakan di SMK Al Amanah, Kecamatan Setu, Kota Tangerang Selatan berjalan sesuai dengan apa yang diharapkan, dimana para peserta bisa mendapatkan input dari materi-materi yang disampaikan narasumber.

a. Materi keorganisasian diharapkan mampu mendidik peserta, para siswa calon dan pengurus OSIS mampu membentuk menjadi bagianbagian yang menyatu, hal ini sesuai dengan konsep dasar manusia sebagai mahluk sosial.

b. Sedangkan untuk materi komunikasi diharapkan memberikan masukan kepada para siswa begitu pentingnya komunikasi di dalam organisasi. Komunikasi memiliki peran dan fungsi tersendiri, sebagai siklus atau putaran yang melibatkan orang-orang dalam hal ini para pengurus OSIS di dalam organisasi.

c. Sedangkan untuk materi motivasi setidaknya mendorong para siswa untuk menjadi pemimpin dan bagaimana 


\section{JURNAL ABDIMAS

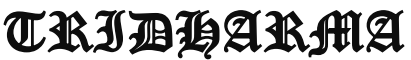

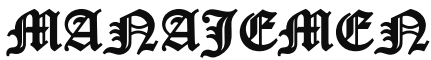

P-ISSN 2715-7105, E-ISSN 2716-070X

Jurnal ABDIMAS Vol. 1, No.2,Mei 2020, Hal (16-24)

@ Prodi Manajemen Fakultas Ekonomi Universitas Pamulang

Email: abdimasjurnal.unpam @ gmail.com Telp: (021) 741-2566
Saran

membangun pola kerjasama yang baik di dalam organisasi. Dalam hal ini, para siswa mendapatkan pandangan bahwa mereka juga patut diberikan penghargaan dalam mengaktualisasikan diri.

d. Kegiatan PKM juga mendapat dukungan penuh dari para civitas sekolah, khususnya para guru dalam hal ini pembina OSIS, lantaran kegiatan PKM ini setidaknya menambah khazanah ilmu pengetahuan yang mungkin saja tidak diperoleh di kelas.

1. Melihat respon dari kegiatan PKM yang dilakukan di SMK Al Amanah Kecamatan Setu, Kota Tangerang Selatan ini, kegiatan PKM sepatutnya masih difokuskan pada sasaran kelompok pelajar.

2. Kegiatan PKM pada sasaran kelompok pelajar hendaknya masih difokuskan pada materimateri yang tidak diterima di bangku sekolah yang konsern terhadap peningkatan wawasan, keterampilan dan mental spiritual.

3. Kegiatan PKM dengan sasaran kelompok pelajar ini juga dimaksudkan untuk membangun citra-imej-branding Unpam sebagai tujuan untuk melanjutkan pendidikan para pelajar.

\section{DAFTAR PUSTAKA}

Coralie Bryant; Louise G. White. 1982. Managing Development in the Third World. Boulder, Col0: Westview Press.

Qurbani, D., Oktrima, B., \& Tanjung, A. W. (2019). MENDIDIK DAN MENGAJARKAN ANAK UNTUK MENGENAL ALLAH PADA USIA DINI DENGAN METODE STORY TELLING DI TK AL-HIDAYAH PAMULANG, TANGERANG

\author{
SELATAN. Jurnal \\ Pengabdian \\ Dharma Laksana, 1(2), 228-239.
}

Devito, joseph

A. 2013.KomunikasiAntarManusia. Profesional Books.

Hasibuan, Malayu S. P., 2009. ManajemenSumberDayaManusia. Jakarta: BumiAksara.

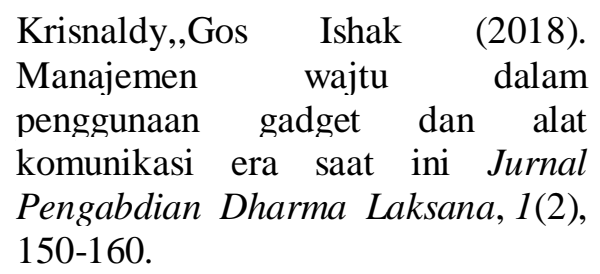

Pasaribu, V. L. D., Agrasadya, A., Shabrina, N., \& Krisnaldy, K. (2020). MENJADI ENTERPRENEUR MUDA YANG MEMILIKI JIWA LEADER UNTUK MENGHADAPI M.... DEPAN. Abdi Laksana, 1(1).

Pasaribu, V. L. D., Elburdah, R. P., Sudarso, E., \& Fauziah, G. (2020). PENGGUNAAN MANAJEMEN WAKTU TERHADAP PENINGKATAN PRESTASI BELAJAR DI SMP ARAISIYAH. Jurnal ABDIMAS, 1(1).

Pasaribu, V. L. D., Susanti, F., \& Hartuti, E. T. K. (2019). MEMOTIVASI SISWA DAN SISWI SMK LETRIS INDONESIA DI DALAM MENENTUKAN PILIHAN UNTUK MELANJUTKAN PENDIDIKAN ATAU BEKERJA SETELAH LULUS SEKOLAH. Jurnal Pengabdian Dharma Laksana, 1(2), 161-172. 


\section{JURNAL ABDIMAS

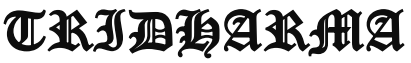

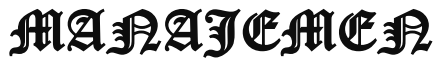

P-ISSN 2715-7105, E-ISSN 2716-070X

Jurnal ABDIMAS Vol. 1, No.2,Mei 2020, Hal (16-24)

@Prodi Manajemen Fakultas Ekonomi Universitas Pamulang

Email: abdimasjurnal.unpam@gmail.com Telp: (021) 741-2566

\section{DOKUMENTASIFOTO KEGIATAN}
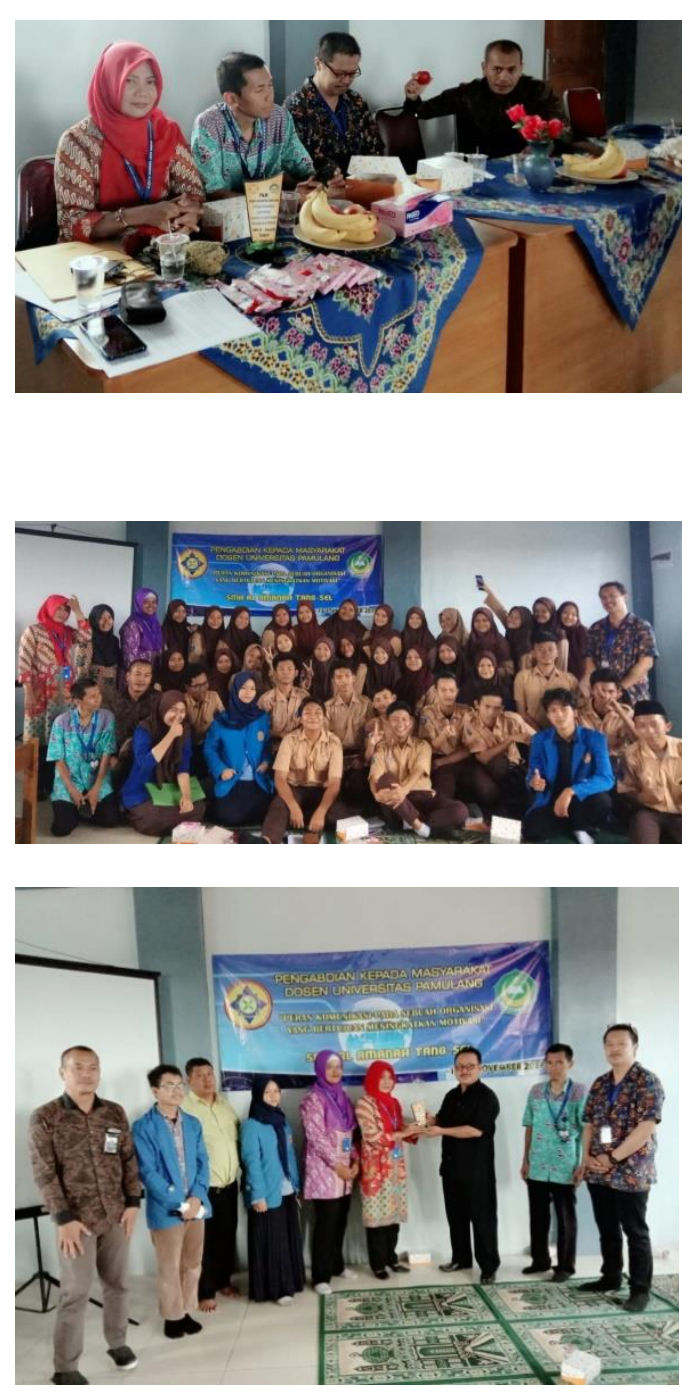